\title{
An Improved Non-isolated LED Converter with Power Factor Correction and Average Current Mode Control
}

\author{
Renbo $\mathrm{Xu}^{1,2,4}$, Hongjian $\mathrm{Li}^{1,2}$, Yongzhi $\mathrm{Li}^{3}$, Changqian Zhang ${ }^{1}$ \\ ${ }^{1}$ School of Physics Science and Technology, Central South University, Changsha, China \\ ${ }^{2}$ School of Materials Science and Engineering, Central South University, Changsha, China \\ ${ }^{3}$ College of Physics and Information Science, Hunan Normal University, Changsha, China \\ ${ }^{4}$ Hunan Information Science Vocational College, Changsha, China \\ E-mail: xrb1118@163.com
}

Received May 3, 2011; revised May 28, 2011; accepted June 5, 2011

\begin{abstract}
A new type of high power LED drivers is proposed by adopting an improved two-stages non-isolated configuration. In order to improve power factor and achieve accurate average current control under universal input voltages ranging from $100 \mathrm{Vrms}$ to $240 \mathrm{Vrms}$, the power factor correction and average current mode control methods operating in continuous current conduction mode are designed and implemented. With the LUMILEDS emitter type LEDs, a laboratory prototype is built and measured. And from the measured results, it could be concluded that the proposed driver has many better performances such as high power factor, low current harmonic, accurate average current control and switch protection.
\end{abstract}

Keywords: High Power LED, Power Factor Correction, Average Current Mode Control

\section{Introduction}

In today's world of lighting applications, many electronic engineers are striving to find out a more energy efficient and cost effective way of driving a lighting source. A new type of lighting sources that has a great potential to replace existing lighting sources such as incandescent and fluorescent lamps in the future is the power lighting emitting diode (LED), which is due to its merits: higher efficiency, superior longevity, continuously-improving luminance and environment friendly [1-3]. This interest in LEDs has prompted many power electronic designers to work on driving LED at higher power factor and output current so that it can be applied broader in lighting applications.

In general lighting applications, the line current harmonics should satisfy the limits set by International Electro technical Commission (IEC) 61000-3-2 class C regulations [4]. And the input current power factor should be higher than 0.9 required by the Energy-Star [5]. Moreover, with only a small change in the LED current, the corresponding luminous flux and luminous efficiency will change by orders of magnitude. In order to avoid big luminous flux change and meet those regulations, the LED driver should have the power factor correction
(PFC) ability and constant average current control.

In view of the development of PFC technology, PFC could be achieved either by passive circuit or by active circuit. With passive PFC, which uses only inductors and capacitors to improve power factor, it is difficult to meet those requirements and become a good candidate because of the disadvantages of high total harmonic distortion (THD) and bulky size [6,7]. In order to overcome these disadvantages, active PFC technology is commonly used in LED drivers due to many advantages such as low THD, fast dynamic response, precise voltage control and universal input voltages. And active PFC method is very suitable for many applications field with high performance requirements, low cost and high control accuracy.

An LED driver with active PFC, which is implemented with two stages, is shown in Figure 1. The two-stages structure has many advantages: avoiding the Electro Magnetic Interference (EMI) if only the two stages operate in trailing edge and leading edge respectively; decreasing the capacitance of the output capacitor; reducing the bulk and extending the longevity efficiently [8-12]. The first stage is used to provide a stable voltage for the post stage with $\mathrm{AC} / \mathrm{DC}$ conversion at the universal input voltage, while the post stage is used for the DC/DC conversion. Unlike conventional LED drivers, it could be 
applied to both low and high voltage cases, such as it is widely used in car applications because the car power supply voltage is easily changeable $[13,14]$. With the goal to achieve higher power factor and LED constant average current control, the Boost-Buck converter with higher power rating operating in continuous current conduction mode (CCM) with average current mode control (ACMC) is proposed through adding two control blocks: PFC control and ACMC block.

\section{Circuit Description}

From the non-isolated LED Boost-Buck converter circuit diagram, it can be seen that the converter consists of rectifier bridge, boost circuit, buck circuit, driving signal and the load. And the Boost-Buck converter uses capacitor as energy transfer component between the first and post stage rather than the inductor mostly used in other conventional converters. It can be known from the analysis that the Boost-Buck converter features fast transient response and excellent frequency response, allowing highly stable feedback regulation to be achieved with simple circuit [15-17]. Two inductors at both input and output side are working in continuous current conduction mode. The inductor ripple current is low and continuous, which can greatly reduce the requirements of input and output filter capacitor. All switch nodes in the circuit are isolated between the two inductors, input and output nodes have no effect on each other, which would make the radiation EMI (Electro Magnetic Interference) from the converter minimized. The operational principles are described and discussed in the next sections.

When the metal oxide semiconductor field effect transistor (MOS-FET) $S_{1}$ is turned on, current flows through the rectifier bridge, the input inductor $L_{1}$ and the MOS switch $S_{1}$. The power supply stores energy in the inductor $L_{1}$ and the diode $V_{D_{1}}$ is off at the moment. When $S_{1}$ turns off, current in $L_{1}$ flows through the diode $V_{D_{1}}$, into the capacitor $C_{1}$ and transfer the energy to storage capacitor $C_{1}$ as a power supply for the post stage Buck converter. When the MOS switch $S_{2}$ is turned on, current flows through the capacitor $C_{1}$, the power switch $S_{2}$, inductor $L_{2}$, capacitor $C_{2}$ and LED strings. Transfer the energy to the capacitor $C_{2}$ and provide power supply to the load LED strings and the diode $V_{D_{2}}$ is turned off synchronously. When $S_{2}$ turns off, current in inductor $L_{2}$ flows through the LED strings and the free-wheeling diode $V_{D_{2}}$.

From the analysis it can be known that the average voltage on the inductor $L_{1}$ is zero as described in Equation (1).

$$
V_{L_{1}} t_{o n_{1}}=V_{L_{1}} t_{o f f_{1}}
$$

where $t_{o n_{1}}$ and $t_{o f f_{1}}$ represent the turn-on and the turn-off time of the MOS switch $S_{1}$ in a switching period. According to the operational principle described in the former, Equation (1) can be rewritten as

$$
V_{i} D_{1} T_{S}=\left(V_{C_{1}}-V_{i}\right)\left(1-D_{1}\right) T_{S}
$$

where $D_{1}$ is the duty ratio of $S_{1}$ and $T_{S}$ is the switching period. Solving Equation (2) for $V_{C_{1}}$ as shown in Equation (3), we can see that the output voltage $V_{C_{1}}$ is increased much.

$$
V_{C_{1}}=\frac{V_{i}}{\left(1-D_{1}\right)}
$$

Taking the same switching period $T_{S}$ and the duty ratio $D_{2}$ of $S_{2}$, from the similar analysis of the inductor $L_{2}$, we have

$$
\left(V_{C_{1}}-V_{O}\right) D_{2} T_{S}=V_{O}\left(1-D_{2}\right) T_{S}
$$

Substituting (3) into (4), the relation between output voltage and input voltage can be obtained by

$$
V_{O}=\frac{D_{2} V_{i}}{\left(1-D_{1}\right)}
$$

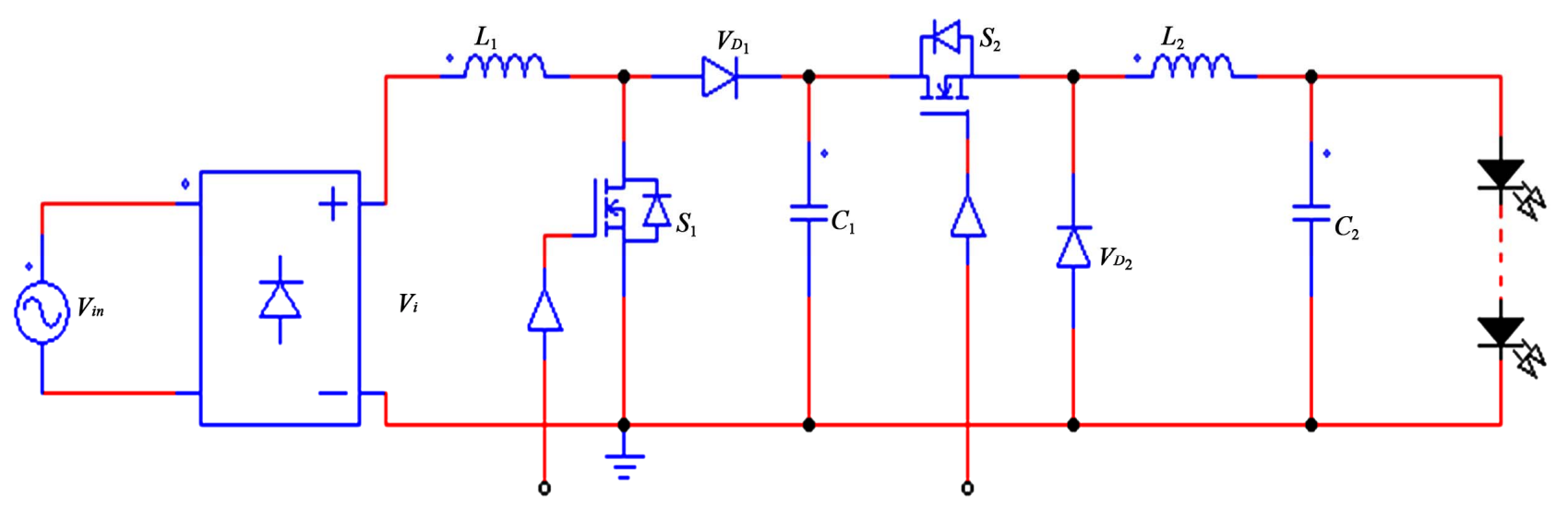

Figure 1. LED Boost-Buck converter diagram. 
From the steady-state operational principle [18], it could be known that the average current flowing through the capacitor $C_{1}$ must be zero defined as

$$
I_{C_{1}} t_{\text {char }}=I_{C_{1}} t_{\text {unch }}
$$

where $t_{\text {char }}$ and $t_{\text {unch }}$ stand for the charging time and uncharging time respectively. (6) could be rewritten as

$$
I_{L_{1}}\left(1-D_{1}\right) T_{S}=I_{L_{2}} D_{2} T_{S}
$$

Solving (7) for $I_{L_{1}}$

$$
I_{L_{1}}=\frac{D_{2} I_{L_{2}}}{\left(1-D_{1}\right)}=\frac{D_{2} I_{O}}{\left(1-D_{1}\right)}
$$

\section{The Proposed Circuit}

From the analysis of the Boost-Buck converter it can be known that the converter has high stability, fast transient response and high efficiency. But the power factor is low because of harmonic distortion and the use of inductors and capacitors, and it can not satisfy the accurate regulation of luminance due to that the light output is proportional to the current delivered to the LEDs string averaged over the utility period. In order to improve the power factor of the input side of the grid and provide a constant average current and lighting output, the technology of active PFC and ACMC is proposed through adding a PFC control loop and an average current control loop as shown in Figure 2.

The boost PFC circuit operates in CCM with trailing edge modulator, while the leading edge modulation is adopted in the Buck pulse width modulation (PWM) constant average current control circuit. Although the switches work under turned-on and turned-off state al- ternately, the proposed converter reduces the harmonic current distortion due to the inductors operated in CCM.

From the system block schematic diagram, it can be known that the error signal between the sampled voltage of the capacitor $C_{1}$ and the reference voltage is amplified and sent to the analog multiplier for generating a halfsine reference current signal as same frequency and phase as input voltage $V_{i}$. The current regulator is used to compare the sensing current $I_{i}$ with the half-sine reference current and then generate a current error amplified signal. Compared with the sawtooth wave, the output of the comparator is the control signal of the MOS switch $S_{1}$. Thus, through adjusting the duty cycle, the current of inductor $L_{1}$ will track the half-sine reference current signal that is to say that the input current $I_{\text {in }}$ tracks the sinusoidal input voltage $V_{\text {in }}$ well for a high power factor.

To get the working stability of current loop and a good dynamic tracking ability of the average inductor current, the current regulator must be designed to have high low-frequency gain, wide mid-frequency gain, a reasonable margin steady and strong switching ripple suppression ability. A compensation network $G(s)$ with two pole and one zero is taken as a current regulator as shown in Equation (9).

$$
G(s)=\frac{\omega_{i}\left(1+s / \omega_{Z}\right)}{s\left(1+s / \omega_{P}\right)}
$$

where $\omega_{i}=\frac{1}{R_{i}\left(C_{1}+C_{2}\right)}, \omega_{P}=\frac{C_{1}+C_{2}}{R_{1} C_{1} C_{2}}, \omega_{Z}=\frac{1}{R_{1} C_{1}}$.

Design goal is to adjust the three parameters to meet the system's open loop frequency domain index. And the specific implement circuit of the current regulator is shown in Figure 3.

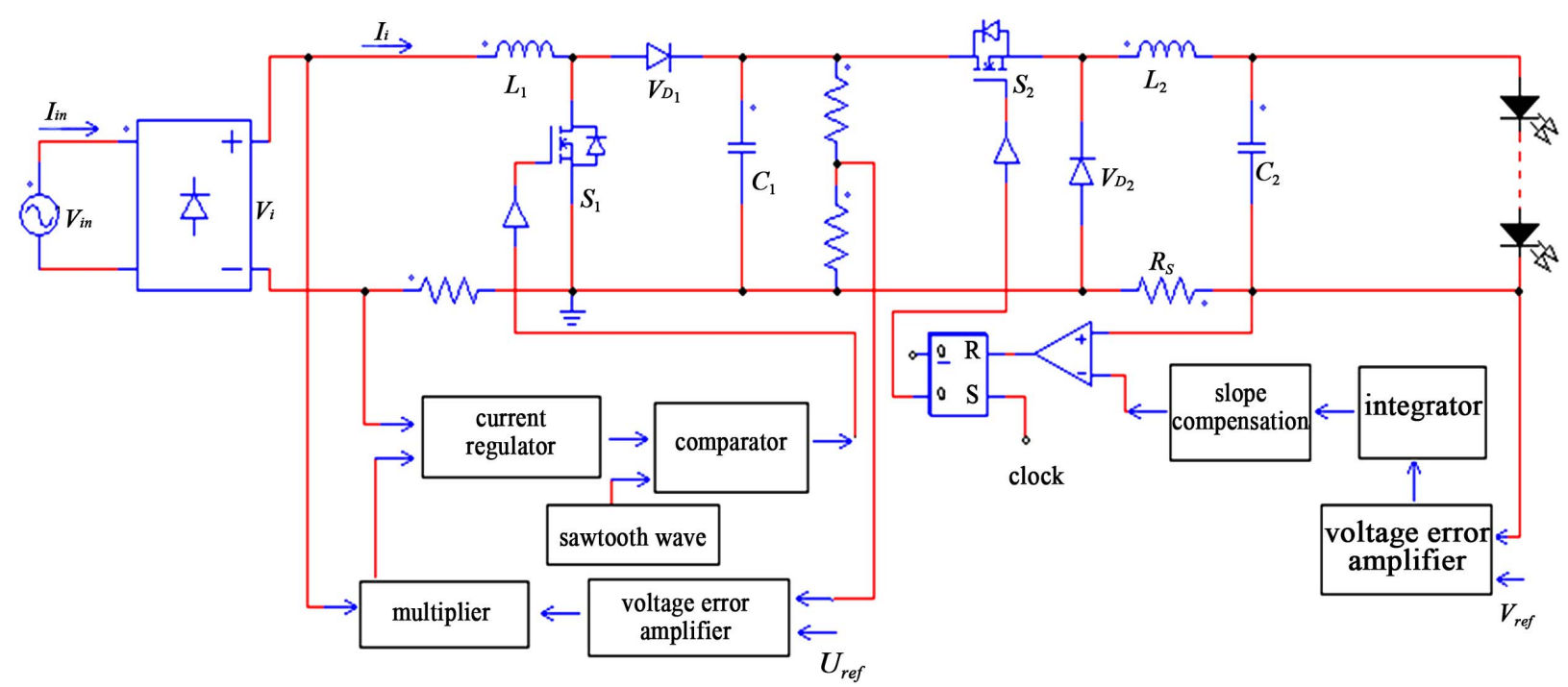

Figure 2. The proposed LED driver with active PFC and ACMC. 
To study the discrete control property of the current regulator, a discrete mathematical mode of current sensing is created and then transformed into $\mathrm{He}(\mathrm{s})$ at the complex frequency domain.

$$
H e(s)=1+\frac{s}{\omega_{n} Q_{z}}+\frac{s^{2}}{\omega_{n}^{2}}
$$

where $\omega_{n}=\frac{\pi}{T_{S}}, Q_{z}=-\frac{2}{\pi}$.

To avoid aberrance in the inductor current, PFC voltage error amplifier design can't seek rapidity excessively and the output voltage should be relatively constant in a frequency cycle. From the perspective of frequency analysis, the voltage regulation loop bandwidth should be limited. And proportional integral voltage regulator is a good candidate and its implement circuit is shown in Figure 4.

The transfer function of the voltage regulator is

$$
G u(s)=\frac{g}{s\left(1+s / \omega_{z}\right)}
$$

where $g$ is the proportional integral coefficient, and $\omega_{z}=\frac{2}{C_{1} R_{i}}$ according to the stability analysis.

From the system block diagram in Figure 2, we can see that there is a sensing resistor $R_{S}$ to sense the output current. After the output current flowing through the high power LEDs and $R_{s}$, the sensing feedback voltage can be acquired. The integral voltage of error value between the feedback voltage and the reference voltage $V_{\text {ref }}$ is sent to the slope compensation. Compared with the sensing feedback voltage, the comparator output is obtained to control the $R S$ flip-flop and then the output of $R S$ flip-flop controls the MOS switch $S_{2}$ and regulates the output average current precisely.

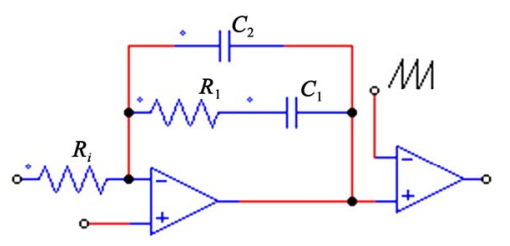

Figure 3. The implement circuit of current regulator.

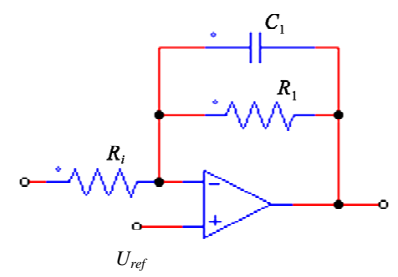

Figure 4. The implement circuit of voltage regulator.
In order to gain the accurate average current, the slope compensation technique is adopted, as shown in Figure 5. $v_{r}$ is the reference voltage, and dotted line $v_{a v r}$ is the average voltage of sensing feedback voltage $v_{s}$ in a switching period. $-m_{s}, m_{r}$ are the slope of the slope compensation voltage and the sensing voltage $v_{s}$ respectively. From the steady-state waveforms, it can be seen that the sensing average voltage $v_{\text {avr }}$ represents the average current of high power LED.

From the steady-state waveforms, we have

$$
\frac{1}{2} m_{r} d T_{S}=v_{r}-v_{a v r}-m_{s} d T_{s}
$$

Take small-signal perturbation of the relevant variables as follows.

$$
\begin{aligned}
& v_{r}=V_{r}+v_{r} \quad v_{a v r}=V_{a v r}+v_{a v r} \\
& m_{r}=M_{r}+m_{r} d=D+\stackrel{\Lambda}{d}
\end{aligned}
$$

Among them, the capitalized letters are steady-state values and the variables with " $\Lambda$ " are small-signal disturbances.

Substituting (12) into (13), we have

$$
\begin{aligned}
& \frac{T_{S}}{2}\left(M_{r}+m_{r}\right)(D+\hat{d}) \\
= & V_{r}+\hat{v}_{r}-V_{a v r}-v_{a v r}-m_{s}(D+\hat{d}) T_{s}
\end{aligned}
$$

With ignorance of second-order small-signal variables, we can get the characteristics equations of $D C$ steadystate (15) and $A C$ small-signal (16).

$$
D=\frac{V_{r}-V_{a v r}}{\frac{1}{2} M_{r} T_{S}+m_{s} T_{s}}=\frac{2}{n M_{r} T_{S}}\left(V_{r}-V_{a v r}\right)
$$

$\operatorname{Among}(15)-m_{s}=-M_{s}, \quad n=1+\frac{2 M_{s}}{M_{r}}$.

$$
\left(\frac{T_{S}}{2} M_{r}+M_{s} T_{s}\right) \stackrel{\Lambda}{d}=v_{r}-v_{a v r}^{\Lambda}-\frac{D T_{s}}{2} m_{r}
$$

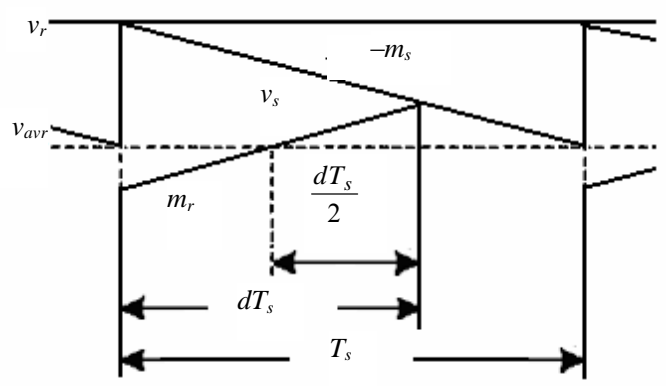

Figure 5. The steady-state waveforms with constant average current control. 
As a result of the new control technique, the driver provides a precise constant average output current and high power factor under pieces of LED series connection. Moreover, the proposed converter operating in CCM has many better performances such as variable input source voltages, wide frequency bandwidth, high efficiency and stability.

\section{Simulation and Experimental Results}

To verify the feasibility of the proposed LED driver, a laboratory prototype with the following specifications were designed and tested.

- Input voltage: 100 - $240 \mathrm{Vrms}$

- Switching frequency: $200 \mathrm{kHz}$

- LED current: $350 \mathrm{~mA}$

The circuit parameters for the laboratory prototype are as follows: the rectifier sampling coefficient is 0.0032; the inductor $L_{1}=1.47 \mathrm{mH}$ and $L_{2}=0.22 \mathrm{mH}$; the capacitor $C_{1}=3500 \mathrm{uF}$ and $C_{2}=470 \mathrm{uF}$, the sensing resistor $R_{S}$ is $0.1 \Omega$ and the reference voltage $V_{r e f}=0.035 \mathrm{~V}$. The series connected LUMILEDS emitter type LEDs is used in this experiment. This LUMILEDS diode is a $1 \mathrm{~W}$ high-luminance LED with a nominal forward voltage of $3.42 \mathrm{~V}$. The laboratory prototype is designed to get a high power factor and a constant output average current $350 \mathrm{~mA}$ when the input source voltage varies from 100 Vrms to 240 Vrms. Figure 6 shows the tested waveforms of the input voltage $V_{\text {in }}$ and input current $I_{i n}$ at the input source voltage of $110 \mathrm{Vrms}$ and $220 \mathrm{Vrms}$, respectively. It could be seen that $I_{\text {in }}$ has a good near-sinusoidal waveform and in phase with the input source voltage $V_{i n}$. Power factor under different input source voltages variations are shown in Figure 7 and the high power factor is over 0.95 .

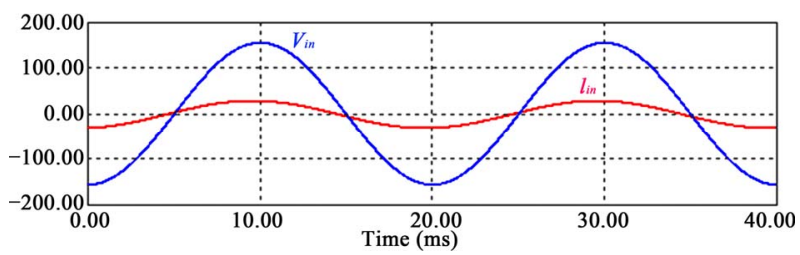

(a)

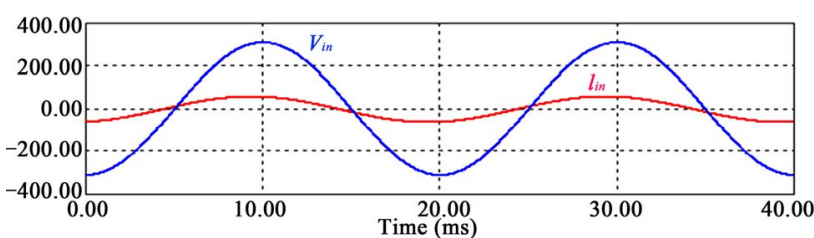

(b)

Figure 6. The tested input voltage and current waveforms at $V_{\text {in }}=110$ Vrms and 220 Vrms. ((a) The tested input voltage and current waveforms at $V_{\text {in }}=110 \mathrm{Vrms}$; (b) The tested input voltage and current waveforms at $V_{\text {in }}=220 \mathrm{Vrms}$ ).
Figure 8 shows that the line-current harmonics are below the limits set by IEC $61000-3-2$ class $C$ regulations with enough margin at the input source voltage of $110 \mathrm{Vrms}$ and $220 \mathrm{Vrms}$, respectively. It can be seen that these high performances such as phase-following, high power factor, low THD are the results of the improved APFC block.

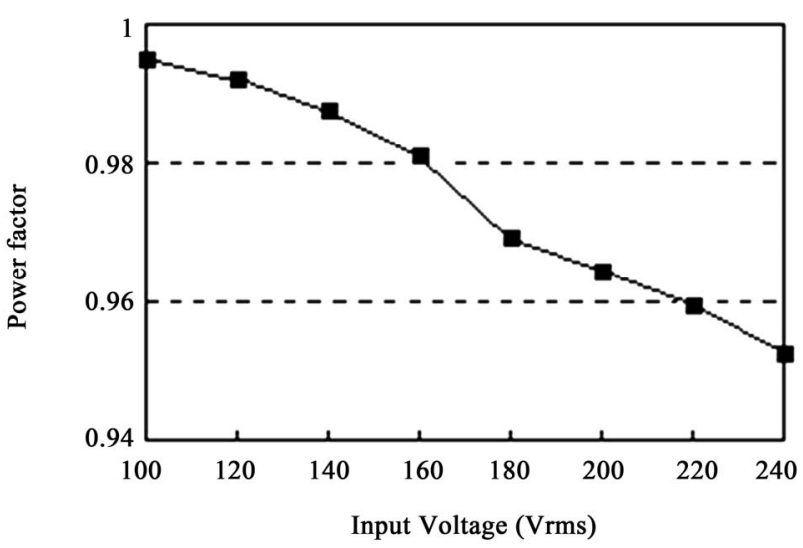

Figure 7. Power factor vs different input voltages.

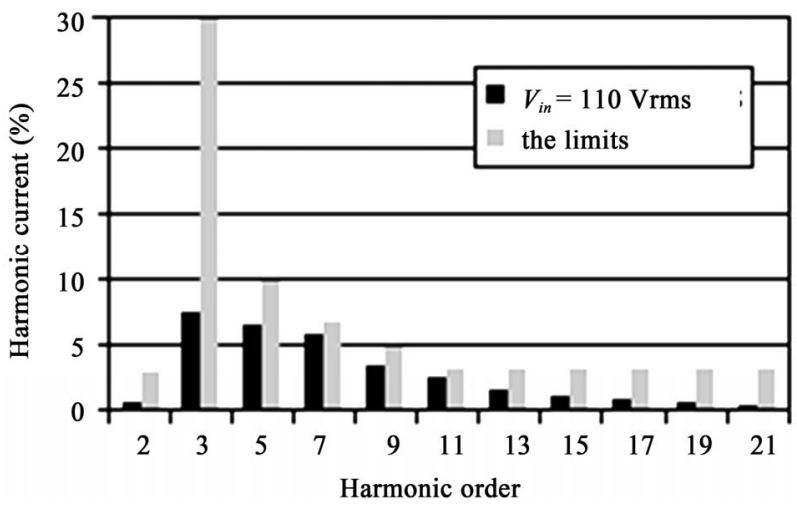

(a)

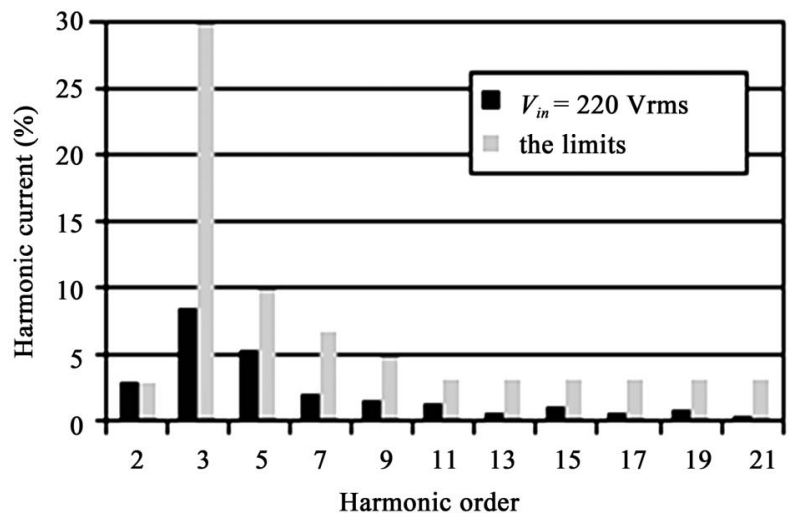

(b)

Figure 8. The measured line-current harmonics at $V_{\text {in }}=110$ Vrms and 220 Vrms. ((a) Line-current harmonics at $V_{\text {in }}=110$ Vrms; (b) Line-current harmonics at $V_{\text {in }}=220$ Vrms). 
Without the ACMC technique, the LED constant average current is $320 \mathrm{~mA}$ below the reference current as shown in Figure 9(a). However, with the proposed method the constant average current of $350 \mathrm{~mA}$ can be achieved as shown in Figure 9(b). It is evident that the LED average current and luminous flux can be regulated by adjusting the duty cycle of MOS-FET switch. And the steady and slowly-rising LED current of the new driver can protect the MOS switch due to the improved ACMC block.

All the test results are consistent with expectations well.

\section{Conclusions}

In this paper, we proposed an improved non-isolated LED converter operating in CCM with PFC and ACMC for driving high power LED lamps. A laboratory prototype with LUMILEDS emitter type LEDs is used to verify the feasibility of the proposed driver. From the measured results, it can be seen that the proposed LED driver achieves a power factor of 0.99 and a THD of $12.2 \%$ at input voltage $110 \mathrm{Vrms}$ and a power factor of 0.96 and a THD of $10.4 \%$ at input voltage 220 Vrms. Many better

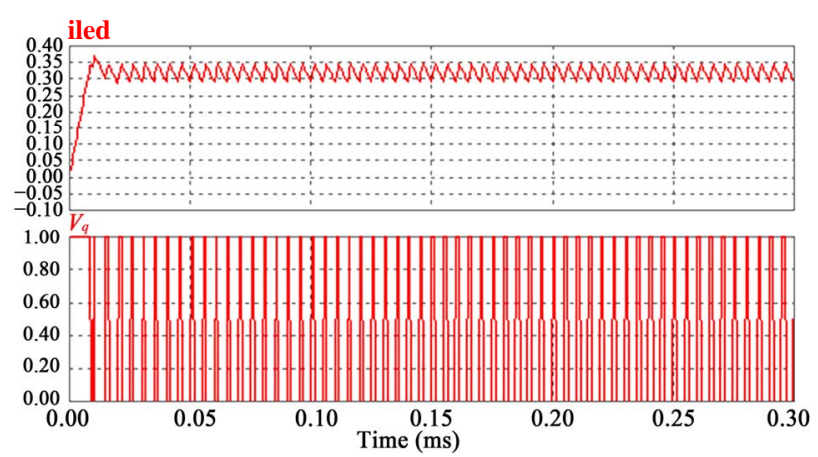

(a)

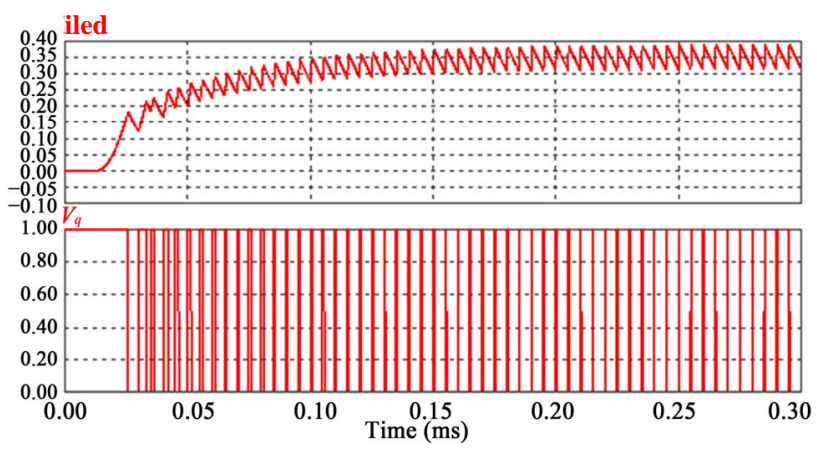

(b)

Figure 9. The LED current simulated waveforms and the switching signal. ((a) The LED current simulated waveforms and the switching signal Without the ACMC; (b) The LED current simulated waveforms and the switching signal With the ACMC). performances such as high power factor, accurate average current control, low current harmonic and switch protection are confirmed and the experimental results match well with the analysis results.

\section{References}

[1] J. Y. Tsao, "Solid-State Lighting: Lamps, Chips and Materials for Tomorrow," IEEE Circuits Devices Magazine, Vol. 20, No. 3, 2004, pp. 28-37. doi:10.1109/MCD.2004.1304539

[2] T. Komine and M. Nakagawa, "Fundamental Analysis for Visible-Light Communication System Using LED Lights," IEEE Transactions on Consumer Electronics, Vol. 50, No. 1, 2004, pp. 100-107. doi:10.1109/TCE.2004.1277847

[3] R. Mehta, D. Deshpande, K. Kulkarni, S. Sharma and D. Divan, "LEDs-A Competitive Solution for General Lighting Applications," IEEE Energy 2008, Atlanta, 17-18 November 2008, pp. 1-5. doi:10.1109/ENERGY.2008.4781063

[4] "Electromagnetic Compatibility (EMC), Part 3-2: Limits-Limits for Harmonic Current Emissions (Equipment Input Current $\leq 16$ A per Phase)," International Standard IEC 61000-3-2, 2001.

[5] Energy Star Program Requirements for Solid State Lighting Luminaries. USA, 2007.

[6] J. P. Noon, "Designing High-Power Factor Off-Line Power Supplies," Proceedings of Unitrode Power Supply Design Seminar Manual SEM1500, Texas Instruments, August 2003, pp. 2-6.

[7] C. K. Tse, "Circuit Theory of Power Factor Correction in Switching Converters," International Journal of Circuit Theory and Applications, Vol. 31, No. 2, 2003, pp. 157-198.

[8] H. van der Broeck, G. Sauerlander and M. Wendt, "Power Driver Topologies and Control Schemes for LEDs," IEEE Applied Power Electronics Conference, Anaheim, 25 February-1 March 2007, pp. 1319-1325.

[9] G. Spiazzi and J. P. Pomilio, "Interaction between EMI Filter and Power Factor Pre-regulators with Average Current Control: Analysis and Design Considerations," IEEE Transactions on Industrial Electronics, Vol. 46, No. 3, 1999, pp. 577-584. doi:10.1109/41.767065

[10] M. Ogata and T. Nishi, "Gragh-Theoretical Approach to 2-Switch DC-DC Converters," International Journal of Circuit Theory and Applications, Vol. 33, No. 2, 2005, pp. 161-173. doi:10.1002/cta.311

[11] A. Lazaro, A. Barrado, M. Sanz, V. Salas and E. Olias, "New Power Correction AC-DC Converter with Reduced Storage Capacitor Voltage," IEEE Transactions on Industrial Electronics, Vol. 54, No. 1, 2007, pp. 384-397. doi:10.1109/TIE.2006.888795

[12] B. Sharifipour, J. S. Hung, P. Liao, L. Huber and M. M. Jovanovic, "Manufacturing and Cost Analysis of PowerFactor-Correction Circuits," IEEE Applied Power Electronics Conference and Exposition, Anaheim, 15-19 February 1998, pp.490-494. 
doi:10.1109/APEC.1998.647734

[13] M. Rico-Secades, A. J. Calleja, J. Ribas, E. L. Corominas, J. M. Alonso, J. Cardesin and Garcia-Garcia, "Evaluation of a Low-Cost Permanent Emergency Lighting System based on High-Efficiency LEDs," IEEE Transactions on Industry Applications, Vol. 41, No. 5, 2005, pp. 1386-1390. doi:10.1109/TIA.2005.853389

[14] Z. Y. Chen, H. L. Yin and P. Li, "Power Quality Problem and New Technology for Its Improvement," Power System Technology, Vol. 26, 2007, pp. 67-70.

[15] M. X. Han, Y. You and H. Liu, "Principle and Realization of Dynamic Voltage Regulator Based on Line Voltage Compensating," Proceedings of the CSEE, Vol. 23, 2003, pp. 49-53.
[16] S. Wall and R. Jackson, "Fast Controller Design for Single-Phase Power-Factor Correction Systems," IEEE Transactions on Industrial Electronics, Vol. 44, No. 5, 1997, pp. 654-660. doi:10.1109/41.633465

[17] W. Aloisi and G. Palumbo, "Efficiency Model of Boost DC-DC PWM Converters," International Journal of Circuit Theory and Applications, Vol. 33, No. 5, 2005, pp. 419-432. doi:10.1002/cta.329

[18] Y. Yueh-Ru and C. Chern-Lin, "Steady-State Analysis and Simulation of a BJT Self-Oscillating ZVS-CV Ballast Driven by a Saturable Transformer," IEEE Transactions on Industrial Electronics, Vol. 46, No. 2, 1999, pp. 249-260. doi:10.1109/41.753763 